\section{DRUG RESISTANCE}

\section{Unable to resist}

Initial excitement about the success of the ABL inhibitor STI-571 (Gleevec) has been tempered by reports of drug resistance. Wolf-K. Hofmann and colleagues have now developed a microarray-based approach to predict which patients will become resistant to the drug - before they've even started to take it.

Gleevec was initially developed to treat chronic myelogenous leukaemia (CML). CML cells have a chromosomal translocation - the Philadelphia chromosome $(\mathrm{Ph})$ - that encodes the BCR-ABL fusion protein, a dysregulated form of the ABL tyrosine kinase. A subset of acute lymphoblastic leukaemias (ALLs) are also $\mathrm{Ph}^{+}$. Might Gleevec be an effective therapy for $\mathrm{Ph}^{+}$ALL? Unfortunately, people with $\mathrm{Ph}^{+} \mathrm{ALL}$ are frequently resistant to Gleevec from the outset (primary resistance) or develop resistance shortly after beginning therapy (secondary resistance). Hofmann and colleagues used oligonucleotide microarrays to find out whether differences in gene expression can distinguish Gleevec-sensitive from Gleevecresistant ALL, using bone-marrow samples taken from patients before and during treatment with Gleevec.

Their analysis reveals 95 genes that are expressed differentially, before treatment, in Gleevec-sensitive patients compared with patients who have primary resistance. A further 56 genes changed their expression levels during treatment of those patients who developed secondary resistance. Secondary resistance was associated with overexpression of Bruton's tyrosine kinase (BTK) and two mitochondrial ATP synthetases (ATP5A1 and ATP5C1), as well as downregulation of the pro-apoptotic gene BAK1 and the cyclindependent kinase inhibitor INK4B. This provides some testable hypotheses as to how Gleevec-resistant cells overcome their need for BCR-ABL, and some potential targets for overcoming Gleevec resistance in those patients who develop it. In the future, it might

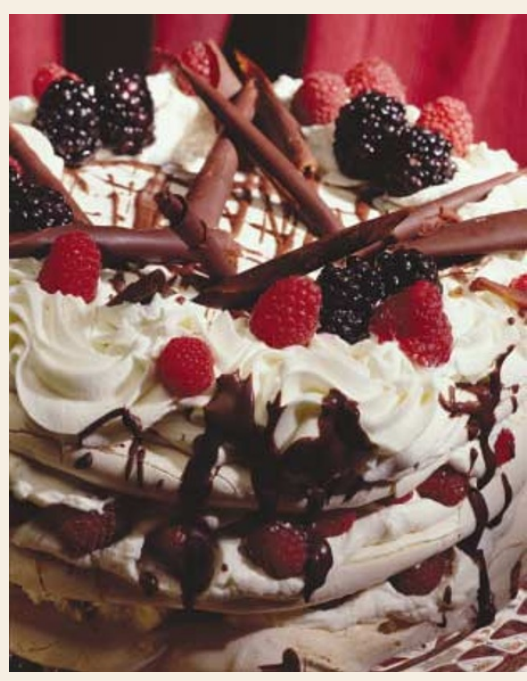

be possible to test ALL patients for resistance before they begin therapy, and give them appropriate drugs if resistance does develop. Cath Brooksbank

(2) References and links ORIGINAL RESEARCH PAPER Hofmann, W.-K. et al. Relation between resistance of Philadelphia-chromosomepositive acute lymphoblastic leukaemia to the tyrosine kinase inhibitor STI571 and gene expression profiles: a geneexpression study. Lancet 359, 481-486 (2002)

\title{
DIAGNOSTICS
}

\section{Predicting outcome}

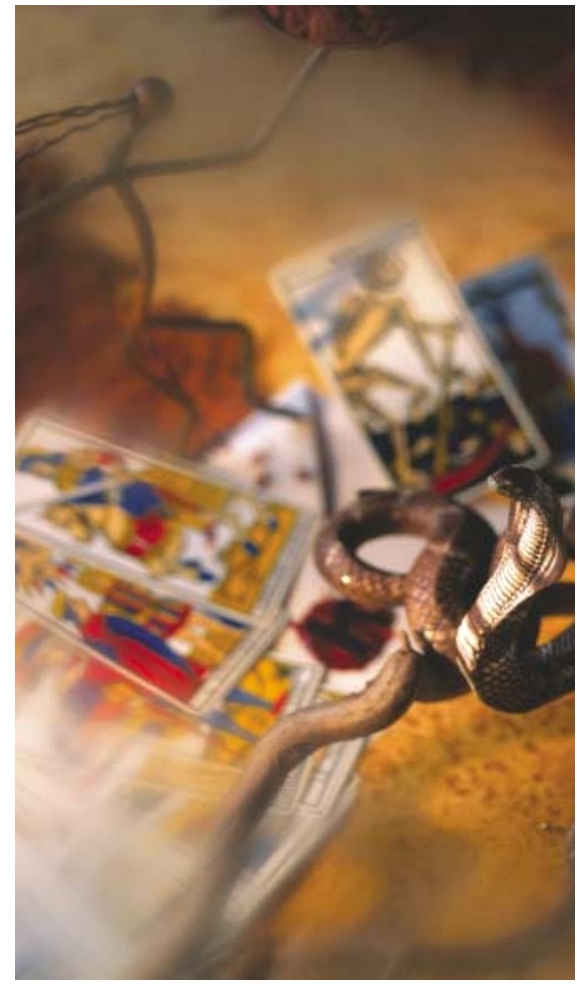

One of the reasons that treatment for paediatric acute lymphoblastic leukaemias (ALLs) has been so successful, achieving long-term eventfree survival rates of almost $80 \%$, is that the intensity of treatment is precisely tailored to the patient's risk of relapse. After diagnosis, patients are placed into a specific 'risk group' that is based on immunophenotype, cytogenetic and molecular diagnostic data. Therapy is then carefully selected to avoid undertreatment or overtreatment. Accurate assignment of patients to specific risk groups is a difficult and expensive process, however, requiring a large number of laboratory tests and health-care professionals. So could gene-expression profiling be an easier way to predict therapeutic response?

In the March issue of Cancer Cell, James Downing's group reports the use of oligonucleotide microarrays to analyse the expression patterns of 12,600 genes from leukaemic blasts of 360 paediatric ALL patients. The expression profiles were able to identify specific leukaemia subtypes, including $E 2 A-P B X 1, B C R-A B L$, $T E L-A M L 1$ and $M L L$ gene rearrangement, hyperdiploidy and T-lineage leukaemias ( $\mathrm{T}$ ALL), with a diagnostic accuracy of $96 \%$. The study also revealed some new leukaemia-associated genes, such as the $M E R$ receptor tyrosine kinase in $E 2 A-P B X 1$, which might be developed as a therapeutic target.

But most importantly, the analysis was able to predict which patients were most likely to undergo relapse. For T-ALL and hyperdiploid subgroups, expression profiling predicted which cases would relapse with an accuracy of $97 \%$ and $100 \%$, respectively. There was no single common expression profile that predicted relapse, indicating that a unifying mechanism might not exist.

The authors suggest that this approach could be developed as a more straightforward means of identifying patients who are most likely to undergo relapse or therapy-induced acute myeloid leukaemia (AML) - the main causes of treatment failure in paediatric acute leukaemia. Gene-profiling approaches might also be developed to identify patients who are at risk of developing other therapy-induced complications, such as organ toxicity or infection.

(1) References and links

Kristine Novak

ORIGINAL RESEARCh PAPER Yeoh, E. et al. Classification, subtype discovery, and prediction of outcome in pediatric acute lymphoblastic leukemia by gene expression profiling. Cancer Cell 1, 133-143 (2002)

FURTHER READING Armstrong, S. A. et al. MLL translocations specify a distinct gene expression profile that distinguishes a unique leukemia. Nature Genet. 30, 41-47 (2001)

\section{WEB SITE}

James R. Downing's lab:

http://www.stjude.org/departments/downing.htm 